\title{
Learning Symbolic Rules with a Reactive with Tags Classifier System in Robot Navigation
}

\author{
Araceli Sanchis, José M. Molina, Pedro Isasi, Javier Segovia* \\ Sca-Lab. Departamento de Informática. \\ Universidad Carlos III de Madrid, Spain. \\ Avda. Universidad 30, 28911-Leganés (Madrid). \\ e-mail : masm@ia.uc3m.es \\ * Departamento de Lenguajes y Sistemas, Facultad de Informática, UPM \\ Campus de Montegancedo, Boadilla del Monte (Madrid)
}

\begin{abstract}
Classifier System are special production systems where conditions and actions are codified in order to learn new rules by means of Genetic Algorithms (GA). These systems combine the execution capabilities of symbolic systems and the learning capabilities of Genetic Algorithms. The Reactive with Tags Classifier System (RTCS) is able to learn symbolic rules that allow to generate sequence of actions, chaining rules among diferent time instants, and react to new environmental situations, considering the last environmental situation to take a decision. The capacity of RTCS to learn good rules has been prove in robotics navigation problem. Results show the suitablity of this aproximation to the navigation problem and the coherence of extracted rules.
\end{abstract}

\section{Introduction}

A Classifier System, proposed by John Holland [1, 2, 3, 4, 5, 6, 7], is a kind of production system. In general, a production system is a set of rules that trigger others and accomplish certain actions. Rules consist of a condition and an action. An action can activate the condition of other rule, and thus some rules interact on other. Classifier Systems are parallel production systems while traditional expert systems, generally, are not parallel. In a parallel production system several rules can be activated at the same time, while in not parallel ones, only one rule can be activated in each action. Together with the parallel activation capacity of rules, CS's have the property of learning rule chains sintactically simple to guide their behavior in changing environments, therefore they are considered as learning systems.

In traditional production systems, the value of a rule with respect to other is fixed by the programmer in conjunction with an expert or group of experts in the matter that is being emulated. In a CS does not exist this advantage. The relative value of the different rules is one of the key pieces of the information that it must be learnt. To facilitate this learning, the CS force rules to coexist in an information-based service economy. It is held a competition among rules, where the right to answer to the activation is going from the highest bidders, that will pay the value of their offers to those rules responsible of their activation. The competitive nature of the economy assures that good rules (usefull ones) survive and bad rules disappear.

When a CS is employed for learning reactive behaviors, an additional problem is detected respect to the action chains: these action chains blind the system, make it insensitive to the environment during the duration of the chain, since the system can 
not manage any new input during the decision process. If, furthermore, the environment where the learning is accomplished is dynamical, the system would have to read the sensors (input, situation of the environment) in each decision step, since this is the principal characteristic of reactive systems. To solve this problem, a Reactive with Tags Classifier System, RTCS, is proposed [8], [9]. For example, in the navigation of an autonomous robot through a dynamical environment problem studied (where the obstacles can be mobiles), robot would not have to remain blind any moment, therefore each movement must be the result of the application of a decision process over the last reading of the sensors [10]. Control rules could be designed by a human expert, designed "ad-hoc" for the problem, or learnt through some artificial intelligence techniques. Some approximations have employed Genetic Algorithms to evolve Fuzzy controllers [11], Evolutionary Strategies to evolve connections weights in a Braitenberg approximation [12], or Neural Nets for behaviors learning [13].

In the proposed learning system, the only previous system information is related to number of inputs (in the robot will be number of sensors), the domain, the number of outputs (in the robot, number of motors) and their description. Thus, the robot controller (the RTCS) starting without information about correct associations between sensors input and motors velocities. From this situation, the system (robot + controller) must be capable from learning to reach the greater degree of fitness to the sensors information. The robot has to discover a set of effective rules, employing past situations experience, and must extract information of each situation, when this is produced. In this way, the system will learn from incremental way and the past experience remains implicitly represented through evolved rules.

\section{Classifier Systems}

A Classifier System consists of three principal components, that can be considered as activity levels. The first level (Action) is the responsible of giving answers (adequate or not) for the resolution of the outlined problem. In this level the rules of the system are found, codified in chains of characters over a restricted alphabet. The Action level produces a response to a given situation. The appropriateness of the given response to the problem to solve is measured through the reward that receives the rule from the environment. The second level (Credits Assignment) evaluates the results obtained in the previous level, distributing the rewards received by the rules that provide the output among rules that have contributed to the activation of each one of final rules (which give the output). As in other reinforcement learning methods, this evaluation can be adjusted applying a reward or payment from the environment, with a high value if the solution is profitable and a punishment or negative value if it is not. In this level, it does not possible to modify, however, the behavior of the system by means of changes in their rules, but it is possible to adjust their values and to establish, in certain measure, a good and wrong rules hierarchy. The task of the third level (Discovery) is to find new process that allows the system to discover new solutions. In this level a Genetic Algorithm is applied. 
Although the search of new rules in CS is based on Genetic Algorithms application over a set of rules, a fundamental difference is the capacity of CS to generate isolated rules that are injected to a set of previously existing rules. Genetic Algorithms provide good results in many problems. However, as their analogous Genetic Programming and Evolutionary Strategies, the evaluation is accomplished on the complete system, without discriminating between different internal parts. If the system is composed of a set of rules, as in the case of the CS, an evaluation on the complete set without individualizing each one of the rules, does not permit to generate new isolated rules. Besides, the application of Genetic Algorithms over rules of Classifier Systems requires an intermediate representation, "codified rules", for genetic operators to act. Classifiers Systems are a specialized form of production system that have been designed to be amenable to the use of Genetic Algorithms [7].

The operation form of Classifier Systems presents some problems in execution time, in the learning of complex strategies, in the definition of the instant to call the GA and, as many other learning systems, in the presentation of the examples to the system. Centering in the first two problems, they are due to existence of internal cycles. These cycles permit the interrelationship among rules in order to produce elaborate solutions. While a CS executes internal cycles, remains isolated for the environmental information. This problem can be described as the necessity of a CS of being capable of "to react" to the stimuli of the environment. The attempts of seeking the "reactivity" in Classifier Systems have been approached from two different perspectives: the increase in the speed process of the system, with the systems ICS and hierarchic CS of Dorigo [14], and on the other hand, the execution of a rule for an input, without internal cycles and then without rules sequence, the HCA of Weib [15] based on Wilson [16] and Grefeenstete [17] works.

In this work, a Reactive with Tags Classifier System (RTCS) has been applied [9]. This RTCS works in the sense of Weib [15], but at the same time allows to elaborate complex strategies. For this, it is necessary to remember the definition of reactivity. A reactive system must decide for each input an action, and each action is determined by an input and in a CS, without losing the capacity of chaining rules in different time instants. For obtain a RTCS the operation of the action level has been modified. The solution proposed, therefore, must unite the capacity from learning without previous knowledge with the capacity of generating some kind of internal subdivision within CS to allow rule categories existence. To carry out this solution should be modified the codification of the rules (classifiers) and a field that represent the type or group which belongs each classifier has been included, named Tags $[8,9]$.

\section{Input and Output Codification}

The codification of information in CS (the design of environmental and output messages) is based on the special problem where CS will be applied. In this work, the CS is used as a controller of an autonomous robot named Khepera [13]. The sensory inputs come in from eight infra-red proximity/ambient sensors. The robot has two wheels controlled by two independent DC motors with incremental encoder that allow any type of movement. Each wheel velocity could be read by a speedometer. 
The sensors (proximity, ambient and speedometer) supply three kinds of incoming information: proximity to the obstacles, ambient light and velocity. Instead of using the eight infra-red sensors individually, they have been grouped giving a unique value from two sensor input values (Figure 1a), reducing the amount of information received by the CS. Representing the goal by a light source, the ambient information lets the robot know the angle (the angle position in the robot of the ambient sensor receiving more light) and the distance (the amount of light in the sensor) (Figure 1b).
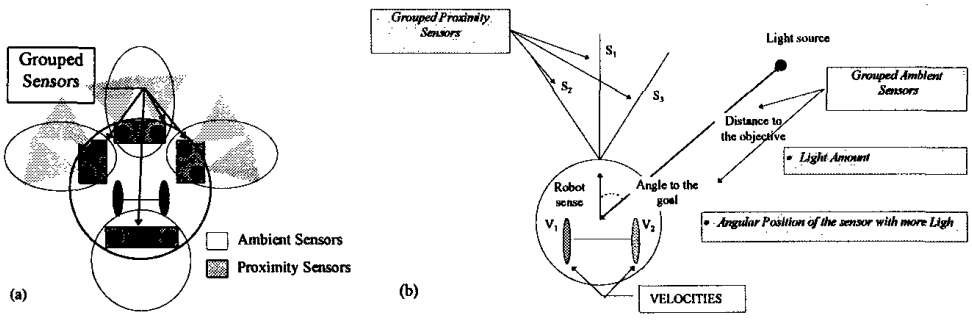

Fig. 1: (a) Sensors in the real robot. (b) Input information to the system.

The input to the CS consists of three proximity sensors, angle and goal distance (given by ambient sensors) and velocity values obtained by the speedometer. The outputs are the velocity values. The composition of the message could be seen in figure 2 .

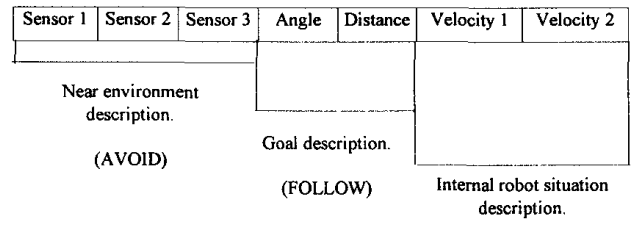

Fig. 2: Composition of the environmental message.

The distance information of proximity sensors is obtained by the response curve of the sensors, that is a sigmoidal function defined over the intensity values domain. The distance domain is transformed, translating it into a simpler domain to codify the values. This transformation allows both the CS and the robot to be independent. So the CS could be developed for any robot by changing the transformation function. The input domain has been partitioned in four crisp sets. The maximum distance value "seen" by one sensor is 40 units and is divided in four equal sets. The angle sets are of different size to consider a fine fitting of the trajectory, avoiding big oscillations when the robot follows the right direction (the sets near 0 and $2 \pi$ are smaller than the " $<\pi$ " and the " $>\pi$ " ones). To keep the independence between robot and CS, the distance values are translated from the real sensor values to a domain defined from 0 to $\infty$. The input domain has been partitioned in four crisp sets. 
Velocity values flow as input to the classifier system and as decision from the CS to the robot. The values are defined by the maximum and minimum velocities $(10,-10)$. This range is divided in four equal sets. All these sets should be codified to build the message from the environment. Two binary digits are needed to represent each set. The codified inputs to the robot are displayed in the table:

\begin{tabular}{|l|l|l|l|l|}
\hline & Proximity & Angle & Distance & Velocities \\
\hline 00 & Very Near (VN) & Near $0(0)$ & $(0,25)(\mathrm{VN})$ & Slow Forward (F) \\
\hline 01 & Near $(\mathrm{N})$ & $<\pi(0-\mathrm{P})$ & $(25,100)(\mathrm{N})$ & Fast Forward $(\mathrm{FF})$ \\
\hline 11 & Far $(\mathrm{F})$ & $>\pi(\mathrm{Pl}-2 \mathrm{PI})$ & $(100,200)(\mathrm{F})$ & Backward $(\mathrm{Bc})$ \\
\hline $\mathbf{1 0}$ & Very liar $(\mathrm{VI})$ & Near $2 \pi(2 \mathrm{PI})$ & $(200, \infty)(\mathrm{VF})$ & Stop $(\mathrm{ST})$ \\
\hline
\end{tabular}

\section{Analysis of Learned Rules in RTCS Applied to Navigation of an Autonomous Robot}

Results obtained with RTCS are caused by, on one hand the introduction of Internal Tags, IT, and, additionally, the introduction of the mechanism that allows the CS to be reactive (RTCS). Evidently, the existence of two mechanisms permits to obtain so good results when applying the CS to the problem of the navigation. In this section, the influence and contribution of Internal Tags will be analyzed. When a RTCS is let to evolve in the simulator, in a certain moment, the RTCS is able of solving the navigation problem. Then is considered that the robot has learnt This RTCS has been carried to the real robot and it has been proven its efficiency in navigation.

The analysis of the meaning of the symbolic rules obtained has been done by different groups. Each group contains a different number of rules and share some condition values that reflect similar situations. In Table 1 - Table 6 appear collected the different groups and the symbolic values for the part of condition can be observed, represented by the concepts s1, s2, s3, A (angle), d (distance), v1 and v2 (left and right wheels velocity values) in the condition part. Below of condition values, message values: $v 1$ and $v 2$ values in message part are found.

Table 1: Group 1 rules.

\begin{tabular}{|c|c|c|c|c|c|c|c|c|}
\hline \multicolumn{7}{|c|}{ CONDFTION } & \multicolumn{2}{|c|}{ MES } \\
\hline s1 & s2 & s3 & $\mathbf{A}$ & d & v1 & $\sqrt{2}$ & v1 & v2 \\
\hline F or VF & VN or $N$ & VF & 0 & $\bar{N}$ & $\mathrm{Bc}$ & $\overline{\mathrm{ST}}$ & $F$ & $\mathrm{~F}$ \\
\hline $\mathrm{VF}$ & MN & $\mathrm{N}$ or $\mathrm{VF}$ & 0 & VF & $\mathrm{F}$ & $\bar{F}$ & $F$ & $\bar{F}$ \\
\hline VF & MN or L & $\mathrm{N}$ or $\mathrm{VF}$ & 0 & VN or $F$ & $\mathbf{F}$ & $\mathrm{F}$ & FF & $\overline{F F}$ \\
\hline F or VF & F or VF & $\mathrm{MN}$ & $0-\mathrm{PI}$ & $\overline{V F}$ & $\overline{\mathrm{Bc}}$ & ST & $F$ & $F$ \\
\hline$F$ or VF & $\mathrm{N}$ or VF & $\mathrm{VN}$ or $\mathrm{N}$ & $2 \mathrm{PI}$ or $0-\mathrm{PI}$ & $\mathrm{VF}$ & $\mathrm{FF}$ & $\mathrm{FF}$ or $\mathrm{Bc}$ & $\mathrm{Bc}$ & ST \\
\hline VF & $\mathrm{VF}$ & MN or L & $0-\mathrm{PI}$ & $\mathrm{VF}$ & FF or $\mathrm{Bc}$ & All & $\mathrm{Bc}$ & ST \\
\hline$F$ or $V F$ & $\mathrm{VN}$ or $\mathrm{N}$ & $\mathrm{VF}$ & 0 -PI & $\mathrm{N}$ & $\mathrm{FF}$ & $\mathrm{FF}$ & ST & $\mathrm{Bc}$ \\
\hline $\mathrm{VF}$ & $\mathrm{VN}$ or $\mathrm{N}$ & $\mathrm{VF}$ & 0 -PI & F or VF & ST or $F$ & $\overline{B c}$ & ST & $\overline{\mathrm{Bc}}$ \\
\hline VF & $\mathrm{VN}$ or $\mathrm{N}$ & $\mathrm{VF}$ & 0 -PI & $\mathrm{F}$ & $\mathrm{F}$ or $\mathrm{FF}$ & $\overline{\mathrm{FF}}$ & ST & $\overline{\mathrm{Bc}}$ \\
\hline $\mathrm{VF}$ & $\mathrm{N}$ or VF & VN or $N$ & 2PI or 0-PI & $F$ & F or FF & FF & $\overline{B c}$ & ST \\
\hline$F$ or $V F$ & $\overline{\mathrm{VF}}$ & $\overline{\mathrm{MN}}$ & 0 or $\mathrm{PI}-2 \mathrm{PI}$ & $\mathrm{VF}$ & ST or Bc & ST or $B c$ & $\mathrm{Bc}$ & $\overline{\text { ST }}$ \\
\hline $\mathrm{F}$ or $\mathrm{VF}$ & $\mathrm{MN}$ & $\mathrm{VF}$ & 2PI or $\mathrm{PI}-2 \mathrm{PI}$ & $\mathrm{VF}$ & ST or F & $\mathrm{Bc}$ & $F$ & $\mathrm{~F}$ \\
\hline VF & $\mathrm{VN}$ or $\mathrm{N}$ & $\mathrm{VF}$ & PI-2PI & $\mathrm{N}$ or $\mathrm{VF}$ & ST or $\mathrm{Bc}$ & $\mathrm{ST}$ & $F$ & $\mathrm{~F}$ \\
\hline MN & $\mathrm{F}$ or $\mathrm{VF}$ & $\mathrm{VF}$ & 0 or $\mathrm{PI}-2 \mathrm{PI}$ & $\mathrm{F}$ or $\mathrm{VF}$ & $\mathrm{Bc}$ & ST & $\mathrm{Bc}$ & ST \\
\hline VN or $\mathrm{N}$ & VF & $\mathrm{VF}$ & $0-\mathrm{PI}$ & $V F$ & All & ST & $F$ & $F$ \\
\hline
\end{tabular}




\begin{tabular}{|c|c|c|c|c|c|c|c|c|}
\hline VN or N & VF & VF & 2PI & N & F & ST or F & ST & Bc \\
\hline VN or N & VF & VF & 0-PI & VF & All & F & F & F \\
\hline VF & MN & VF & N & VF & ST & Bc & F & F \\
\hline VF & VF & MN & 0 -PI & F & All & ST or Bc & Bc & ST \\
\hline F or VF & VF & MN & 0 & F & FF or Bc & ST or Bc & F & F \\
\hline
\end{tabular}

Group 1 consists of 20 rules of the 119 that RTCS contains. Analyzing the sensors values $s 1, s 2$ and $s 3$ in the rules of group 1 , this group seems to have in common that represents situations of collision danger in some of the sensors. It does not seem be a group that answer solely to this characteristic, since collision danger appears frequently in only one sensor. Furthermore, if values of velocities decided for each situation are analyzed, turnings and advances of the robot are observed, though rules number that make the robot turns is not very high. Angle values are those which, compel the robot to advance without turning when collision risk appears by the lateral (values $\mathrm{s} 2$ and $\mathrm{s} 3$ ).

Table 2: Group 2 rules.

\begin{tabular}{|c|c|c|c|c|c|c|c|c|}
\hline \multicolumn{7}{|c|}{ CONDITION } & \multicolumn{2}{|c|}{ MES } \\
\hline S1 & $\mathbf{s 2}$ & s3 & $\mathbf{A}$ & $\mathbf{d}$ & v1 & $\sqrt{2}$ & v1 & v2 \\
\hline $\mathrm{VN}$ & $\mathrm{VN}$ & $\mathrm{VF}$ & 0-PI & $\mathrm{N}$ or $\mathrm{VF}$ & $\mathrm{FF}$ & $\mathrm{FF}$ & ST & $\overline{\mathrm{Bc}}$ \\
\hline $\mathrm{N}$ or VF & $\mathrm{VN}$ or $\mathrm{N}$ & F or VF & 0 or $0-\mathrm{PI}$ & $F$ & $\mathrm{~F}$ or $\mathrm{FF}$ & $\overline{F F}$ & ST & $\overline{\mathrm{Bc}}$ \\
\hline $\mathrm{N}$ or $\mathrm{VF}$ & $\mathrm{VN}$ & $\mathrm{VF}$ & 0 or PI-2PI & $F$ & $\mathrm{FF}$ & $\mathrm{FF}$ or $\mathrm{Bc}$ & $\mathrm{FF}$ & $\mathrm{FF}$ \\
\hline VN & VN or $F$ & $\mathrm{VN}$ & 0-PI & $\mathrm{VF}$ & $\mathrm{F}$ or $\mathrm{FF}$ & FF or $B c$ & $\mathrm{Bc}$ & ST \\
\hline $\mathrm{N}$ & $F$ & $\mathrm{VN}$ & 0-PI & $\mathrm{VF}$ & $\mathrm{Bc}$ & ST & $\mathrm{Bc}$ & ST \\
\hline VN or $N$ & $\mathrm{~N}$ or VF & VN or $F$ & 0 & $\mathrm{VF}$ & $\mathrm{Bc}$ & all & $\mathrm{Bc}$ & ST \\
\hline $\mathrm{N}$ or VF & VN or $\mathrm{N}$ & VF & $0-\mathrm{PI}$ & $\overline{V F}$ & $\mathrm{~F}$ & $\mathrm{~F}$ & ST & $\mathrm{Bc}$ \\
\hline $\mathrm{VN}$ or $\mathrm{N}$ & VN or F & VN or F & $2 \mathrm{PI}$ & $\mathrm{VF}$ & ST & all & $\mathrm{Bc}$ & ST \\
\hline $\mathrm{N}$ & $\mathrm{F}$ & VN or F & PI-2PI & $\mathrm{VF}$ & FF & FF & $\overline{\mathrm{Bc}}$ & ST \\
\hline $\mathrm{VN}$ or $\mathrm{F}$ & VF & $\mathrm{F}$ & PI-2PI & F or VF & $\mathrm{Bc}$ & ST & $\overline{B c}$ & $\overline{\text { ST }}$ \\
\hline $\mathrm{N}$ & $\mathrm{N}$ or VF & $\mathrm{VN}$ & $2 \mathrm{PI}$ or $\mathrm{PI}-2 \mathrm{PI}$ & $\mathrm{F}$ or $\mathrm{VF}$ & $\overline{B c}$ & ST & FF & FF \\
\hline$F$ & $\mathrm{VN}$ or $\mathrm{N}$ & $\overline{\mathrm{VF}}$ & PI-2PI & $\mathrm{F}$ or $\mathrm{VF}$ & F or FF & $\bar{F}$ & $\mathrm{~F}$ & $\mathrm{~F}$ \\
\hline VN or $\mathrm{N}$ & VN or $F$ & $\mathrm{VF}$ & $0-\mathrm{Pl}$ & $F$ & ST or $F$ & $\mathrm{~F}$ & $\mathrm{FF}$ & $\overline{F F}$ \\
\hline VN or $F$ & $F$ & $\mathrm{~N}$ & $2 \mathrm{PI}$ or $\mathrm{PI}-2 \mathrm{PI}$ & $\mathrm{VF}$ & ST or $F$ & $\overline{\mathrm{BC}}$ & $\mathrm{Bc}$ & $\overline{\mathrm{ST}}$ \\
\hline $\mathrm{VN}$ & $\bar{F}$ & $\mathrm{VN}$ & $0-P I$ & $\mathrm{VF}$ & ST & $\mathrm{Bc}$ & $\mathrm{Bc}$ & ST \\
\hline $\mathrm{VN}$ & $\mathrm{N}$ & $\mathrm{N}$ & all & $\mathrm{VF}$ & ST or F & $\mathrm{Bc}$ & ST & $\mathrm{Bc}$ \\
\hline VN & VN or $N$ & VN or $N$ & 0 -PI & VF & ST or $B c$ & $\mathrm{Bc}$ & ST & $\mathrm{Bc}$ \\
\hline VN or $\mathrm{N}$ & $F$ & VF & $2 \mathrm{PI}$ or $0-\mathrm{PI}$ & VN or $F$ & FF & FF or $\mathrm{Bc}$ & ST & $\overline{\mathrm{BC}}$ \\
\hline$F$ & $\mathrm{VN}$ & $\mathrm{N}$ or VF & PI-2PI & $\mathrm{VF}$ & $\mathrm{FF}$ & FF & ST & $\mathrm{Bc}$ \\
\hline $\mathrm{N}$ or $\mathrm{VF}$ & F or $\mathrm{VF}$ & VN or $F$ & 2PI & $\overline{\mathrm{VF}}$ & all & ST & $F$ & $\bar{F}$ \\
\hline $\mathrm{N}$ & VN or $\mathrm{N}$ & $\mathrm{VF}$ & 0 or $0-\mathrm{PI}$ & $\overline{\mathrm{VF}}$ & $\mathrm{FF}$ & FF & ST & $\overline{B c}$ \\
\hline $\mathrm{N}$ or VF & VF & $\mathrm{VN}$ & PI-2PI & $\mathrm{N}$ or $\mathrm{VF}$ & $\mathrm{FF}$ & $\mathrm{FF}$ & $\mathrm{Bc}$ & ST \\
\hline $\mathrm{N}$ & $\mathrm{N}$ or $\mathrm{VF}$ & VN & 2PI or PI-2PI & $F$ or $V F$ & $\overline{B c}$ & ST & $\overline{\mathrm{Bc}}$ & ST \\
\hline $\mathrm{VN}$ & VN or $N$ & $\mathrm{VF}$ & 0or 0-PI & VF & $\mathrm{F}$ & $\mathrm{F}$ & ST & $\mathrm{Bc}$ \\
\hline $\mathrm{N}$ or $\mathrm{VF}$ & $\mathrm{VN}$ & $\mathrm{VF}$ & PI-2PI & $\mathrm{VF}$ & $\mathrm{F}$ & ST or $F$ & ST & $\overline{\mathrm{Bc}}$ \\
\hline $\mathrm{N}$ & $\mathrm{VN}$ & VF & 0 & $\mathrm{VF}$ & ST or $\mathrm{Bc}$ & ST or $\mathrm{BC}$ & ST & $\overline{B c}$ \\
\hline Nor VF & $\mathrm{VN}$ & $\mathrm{VF}$ & PI-2PI & $\mathrm{VF}$ & FF or $\mathrm{Bc}$ & FF & ST & $\mathrm{Bc}$ \\
\hline$F$ & VN or $F$ & $\mathrm{VF}$ & 0 or $0-\mathrm{PI}$ & $\mathrm{N}$ & ST or F & all & ST & $\overline{B c}$ \\
\hline $\mathrm{N}$ or VF & VN & VF & PI-2PI & $\mathrm{VF}$ & $F$ & ST or F & ST & $\mathrm{Bc}$ \\
\hline
\end{tabular}

Group 2 contains 29 of the 119 ones that forms the RTCS, so appear a $50 \%$ more rules than in previous group. In this group the most important observed characteristic is that appear many values near or very near in sensors $s 1, \mathrm{~s} 2$ or $\mathrm{s} 3$, that 
represent situations where the robot is in danger of collision. Seem, therefore, that it can be concluded that this group is the one which is entrusted with special way with avoiding the obstacles. In this case, the values of the decisive speeds are in such a way that in nearly all the rules is produced the draft of the robot.

Table 3: Group 3 rules.

\begin{tabular}{|c|c|c|c|c|c|c|c|c|}
\hline \multicolumn{7}{|c|}{ CONDITION } & \multicolumn{2}{|c|}{ MES } \\
\hline s1 & s2 & s3 & $\mathbf{A}$ & d & v1 & $\mathbf{v 2}$ & v1 & $\mathbf{v 2}$ \\
\hline VF & VF & VF & 0-PI & $\mathrm{VN}$ or $\mathrm{F}$ & All & ST or F & $\bar{F}$ & $F$ \\
\hline VF & F or VF & F or VF & 0 or $\mathrm{PI}-2 \mathrm{PI}$ & VF & ST & $\mathrm{Bc}$ & $\mathrm{Bc}$ & ST \\
\hline F or VF & $\mathrm{VF}$ & $\mathrm{VF}$ & 0 & $\mathrm{VF}$ & ST & $\mathrm{Bc}$ & FF & FF \\
\hline VF & VF & VF & $2 \mathrm{PI}$ or 0 -PI & All & FF or Bc & ST or Bc & ST & $\mathrm{Bc}$ \\
\hline F or VF & VF & F or VF & $0-\mathrm{PI}$ & VF & FF & $\mathrm{FF}$ & FF & FF \\
\hline F or VF & F or VF & VF & 2PI & $\mathrm{N}$ & FF & FF or Bc & FF & FF \\
\hline VF & VF & F or VF & $2 \mathrm{PI}$ & $\mathbf{N}$ & $\mathrm{F}$ & $\mathrm{ST}$ or $\mathrm{F}$ & FF & FF \\
\hline VF & F or VF & VF & 0 & VF & $F$ & $\overline{\mathrm{F}}$ & $F$ & $F$ \\
\hline VF & $\mathrm{VF}$ & VF & 0 & $F$ & $F$ & $\mathrm{~F}$ & $\bar{F}$ & $\mathbf{F}$ \\
\hline VF & VF & $\mathrm{VF}$ & 0 & $\mathrm{~F}$ & $\mathrm{Bc}$ & $\overline{\mathrm{ST}}$ & $\mathrm{F}$ & $\mathbf{F}$ \\
\hline VF & VF & F or VF & 2PI or 0-PI & VN or N & ST & $\mathrm{FF}$ or $\mathrm{Bc}$ & $\mathrm{F}$ & $\mathbf{F}$ \\
\hline
\end{tabular}

Group 3 consists of 11 rules of the 119 ones that contains the RTCS. In this group there are less rules that in previous ones. Represented situations, by the opposite of two previous groups, do not contain no collision situation, in fact it seems rather than rules of this group are related with angle values. Analyzing angle values for all rules, mostly the robot seems quite aligned with the objective. As result of the inference of each rule, messages sent to the robot compel him to advance in straight line, that corresponds to the situation where the robot is located forming a 0 or $2 \mathrm{PI}$ angle with the objective. Distance values to the objective do not seem, to be determinant to take decisions.

Table 4: Group 4 rules.

\begin{tabular}{|c|c|c|c|c|c|c|c|c|}
\hline \multicolumn{7}{|c|}{ CONDITION } & \multicolumn{2}{|c|}{ MES } \\
\hline s1 & s2 & $\mathbf{s 3}$ & a & d & v1 & $\mathbf{v} 2$ & v1 & $\mathbf{v 2}$ \\
\hline $\mathrm{N}$ & $\mathrm{N}$ or VF & VF & 0 & $\mathrm{VN}$ or $\mathrm{N}$ & $\mathrm{ST}$ or $\mathrm{Bc}$ & $\mathrm{Bc}$ & $\mathrm{FF}$ & FF \\
\hline VF & $\mathrm{N}$ & $\mathrm{VF}$ & 2PI or PI-2PI & VF & $\mathrm{Bc}$ & ST & $\mathrm{F}$ & $F$ \\
\hline $\mathrm{VF}$ & $\bar{N}$ & $\mathrm{~N}$ or VF & PI-2PI & $\mathrm{VF}$ & $\mathrm{F}$ or $\mathrm{FF}$ & $\mathrm{F}$ & $\mathrm{F}$ & $\bar{F}$ \\
\hline$F$ & $\mathrm{VF}$ & $\mathrm{N}$ & 0 -PI & VF & $\mathrm{Bc}$ & ST & $\mathrm{Bc}$ & ST \\
\hline $\mathrm{N}$ & $\mathrm{VF}$ & $\mathrm{F}$ & $0-P I$ & $\overline{\mathrm{VF}}$ & $\mathrm{FF}$ or $\mathrm{Bc}$ & ST & $\mathrm{Bc}$ & ST \\
\hline $\mathrm{N}$ & Nor VF & $\mathrm{N}$ & 0 or $0-\mathrm{PI}$ & All & $\mathrm{Bc}$ & ST or F & $\overline{B c}$ & ST \\
\hline VF & VF & $\mathrm{N}$ & All & $\mathrm{VF}$ & ST & ST or Bc & $\overline{F F}$ & FF \\
\hline $\mathbf{N}$ & $\mathrm{VF}$ & All & $2 \mathrm{PI}$ & $\mathrm{VF}$ & $\mathrm{F}$ & All & $\mathrm{FF}$ & $\overline{\mathrm{FF}}$ \\
\hline $\mathrm{N}$ or VF & $\bar{N}$ & $\mathrm{VF}$ & 2PI or 0-PI & VF & FF & $\mathrm{FF}$ & $\overline{\mathrm{FF}}$ & $\overline{F F}$ \\
\hline$F$ or $V F$ & $\mathbf{N}$ & $\mathrm{N}$ or $\mathrm{VF}$ & 2PI or PI-2PI & $\overline{V F}$ & ST or $\mathrm{Bc}$ & FF or $\mathrm{Bc}$ & $\bar{F}$ & $F$ \\
\hline $\mathrm{F}$ & $\mathrm{N}$ & $\mathrm{VF}$ & $0-P I$ & $\mathrm{~F}$ & $F$ & $\mathrm{~F}$ & $\mathrm{~F}$ & $\mathrm{~F}$ \\
\hline$F$ & $\mathrm{~N}$ & $\mathrm{VF}$ & 2PI or $0-\mathrm{PI}$ & VF & All & $\mathrm{F}$ & ST & $\overline{\mathrm{Bc}}$ \\
\hline $\mathrm{F}$ & $\mathrm{N}$ & F or VF & 0-PI & VF & $\mathrm{FF}$ & $\mathrm{FF}$ or $\mathrm{Bc}$ & ST & $\mathrm{Bc}$ \\
\hline $\mathrm{N}$ or VF & $\mathrm{N}$ & $\mathrm{VF}$ & $0-\mathrm{PI}$ & $\mathrm{VF}$ & $\mathrm{FF}$ & $\mathrm{FF}$ & $\mathrm{FF}$ & FF \\
\hline $\mathrm{F}$ & F or VF & $\mathrm{N}$ & 0 or PI-2PI & $\mathrm{N}$ or $\mathrm{VF}$ & $\mathrm{FF}$ or $\mathrm{Bc}$ & ST & $\mathrm{F}$ & $F$ \\
\hline All & $\mathrm{VF}$ & $\mathrm{N}$ & $2 \mathrm{PI}$ or $\mathrm{PI}-2 \mathrm{PI}$ & $\mathrm{N}$ or $\mathrm{VF}$ & ST or F & $\mathrm{Bc}$ & $\mathrm{Bc}$ & ST \\
\hline$F$ & $\mathrm{~N}$ & VF & $2 \mathrm{PI}$ & VF & $\mathrm{FF}$ & $F$ or $F F$ & ST & $\mathrm{Bc}$ \\
\hline VF & $\mathrm{N}$ & VF & 0 & VF & $\mathrm{F}$ & $F$ & $\mathrm{~F}$ & $F$ \\
\hline
\end{tabular}




\begin{tabular}{|c|c|c|c|c|c|c|c|c|}
\hline F & VF & N & PI-2PI & VF & FF & FF & Bc & ST \\
\hline F or VF & VF & N & 0 or PI-2PI & VN or F & F & F & F & F \\
\hline VF & F or VF & N & 0-PI & F & F & F & F & F \\
\hline
\end{tabular}

Group 4 consists of 21 of 119 rules that contains the RTCS. In this group, any clear tendency appears with respect to the general behaviors: "straight to objective" and "avoid obstacles". Analyzing the rules, some of the proximity sensors, s1, s2 and s3, has values of near, but this value appears in rules joint to Far or Very Far values, so that is no case of danger situations. Attending to the angle and distance values is observed that the robot, in almost all rules, is far from the objective and in general no aligned with the objective. These circumstances cause that rules compel to the robot to turn toward the objective and to advance so that, thereinafter, some danger situation will be produced that groups 1 and 2 could resolve.

Table 5: Group 5 rules.

\begin{tabular}{|c|c|c|c|c|c|c|c|c|}
\hline \multicolumn{7}{|c|}{ CONDITION } & \multicolumn{2}{|c|}{ MES } \\
\hline s1 & s2 & $\mathbf{s 3}$ & $\mathbf{a}$ & d & v1 & v2 & v1 & v2 \\
\hline $\mathrm{VF}$ & $\mathrm{N}$ or VF & $\mathrm{VF}$ & All & $\mathrm{L}$ & ST or Bc & ST or Bc & $\mathrm{FF}$ & $\overline{F F}$ \\
\hline $\mathrm{VF}$ & Áll & $\overline{\mathrm{VF}}$ & 0 & All & FF or $B c$ & ST & FF & FF \\
\hline$\overline{V F}$ & All & $\mathrm{VF}$ & 0 or 0-PI & $\mathrm{N}$ & ST or F & $\mathrm{F}$ & $\bar{F}$ & $F$ \\
\hline VF & All & $\overline{\mathrm{VF}}$ & 0 & All & $\overline{F F}$ or $\mathrm{Bc}$ & $\overline{F F}$ & $\mathrm{FF}$ & FF \\
\hline $\mathrm{VF}$ & $\mathrm{N}$ or $\mathrm{VF}$ & $\mathrm{F}$ & $0-\mathrm{PI}$ & $\mathrm{VF}$ & ST or $B c$ & $\overline{B c}$ & $\mathrm{~F}$ & $\bar{F}$ \\
\hline VF & Nor VF & $\bar{F}$ & 0 -PI & $\overline{V F}$ & All & $\mathrm{F}$ or $\mathrm{FF}$ & ST & $\overline{B c}$ \\
\hline $\mathrm{N}$ or VF & F or VF & $\mathrm{F}$ & 0-PI & $\mathrm{VF}$ & ST & $\mathrm{Bc}$ & $\mathrm{Bc}$ & ST \\
\hline VF & VF & Nor VF & 0-PI & $\mathrm{N}$ or $\mathrm{VF}$ & ST & $\mathrm{Bc}$ & $\overrightarrow{F F}$ & $\mathrm{FF}$ \\
\hline$\overline{V F}$ & All & All & PI-2PI & $\mathrm{VF}$ & ST & ST or F & $\overline{B c}$ & ST \\
\hline VF & $\mathrm{VF}$ & $\mathrm{N}$ or $\mathrm{VF}$ & 2PI or 0-PI & $\overline{V F}$ & $\mathrm{~F}$ & $\mathrm{~F}$ & $F$ & $F$ \\
\hline$\overline{\mathrm{VF}}$ & $\mathrm{VF}$ & $\mathrm{N}$ or $\mathrm{VF}$ & PI-2PI & VNor $N$ & FF & FF or $\mathrm{Bc}$ & $\mathrm{FF}$ & FF \\
\hline $\mathrm{F}$ or $\mathrm{VF}$ & $\mathrm{VF}$ & Nor VF & $2 \mathrm{PI}$ & VF & $F$ & $\mathrm{~F}$ & $\mathrm{~F}$ & $\bar{F}$ \\
\hline Nor VF & $\mathrm{F}$ & $\mathrm{F}$ or $\mathrm{VF}$ & $2 \mathrm{PI}$ & $\mathrm{VF}$ & $F$ & $\mathrm{~F}$ or $\mathrm{FF}$ & $\overline{\mathrm{F}}$ & $\bar{F}$ \\
\hline $\mathrm{VF}$ & $\mathrm{N}$ or $\mathrm{VF}$ & Nor VF & 2PI & F or VF & $\bar{F}$ & ST or F & $\mathrm{F}$ & $\bar{F}$ \\
\hline $\mathrm{N}$ or $\mathrm{VF}$ & $\bar{F}$ & All & $2 \mathrm{PI}$ & $\mathrm{L}$ & ST or F & ST or F & $\bar{F}$ & $\bar{F}$ \\
\hline $\mathrm{VF}$ & VF & $\mathrm{N}$ or VF & $\overline{2 \mathrm{PI}}$ & $\overline{\mathrm{L}}$ & $\mathrm{FF}$ & $\mathrm{FF}$ & $\mathrm{FF}$ & $\mathrm{FF}$ \\
\hline$\overline{\mathrm{VF}}$ & VF & $\mathrm{N}$ or VF & $2 \mathrm{PI}$ & $\mathrm{L}$ & $\bar{F}$ & $\mathrm{~F}$ & $\mathrm{FF}$ & $\overline{\mathrm{FF}}$ \\
\hline VF & All & VF & 0 -PI & $\mathrm{L}$ & $F$ & $F$ & $\mathrm{~F}$ & $\mathrm{~F}$ \\
\hline $\mathrm{N}$ or VF & $\mathrm{N}$ or $\mathrm{VF}$ & F or VF & 0 or 0 -PI & $\mathrm{L}$ & $\overline{\mathrm{F}}$ & $\mathrm{F}$ & $\mathrm{FF}$ & FF \\
\hline VF & $\mathrm{F}$ or $\mathrm{VF}$ & $\mathrm{N}$ or $\mathrm{VF}$ & $2 \overline{\mathrm{PI}}$ & $\mathrm{VF}$ & $\mathrm{FF}$ & $\mathrm{FF}$ & $\overline{F F}$ & FF \\
\hline $\mathrm{VF}$ & $\mathrm{VF}$ & $\mathrm{N}$ or $\mathrm{VF}$ & 2PI or PI-2PI & $\mathrm{L}$ & $\mathrm{ST}$ or $\mathrm{Bc}$ & ST & $\mathrm{Bc}$ & $\overline{\text { ST }}$ \\
\hline $\mathrm{VF}$ & $\mathrm{F}$ or $\mathrm{VF}$ & $N$ or $V F$ & $2 \mathrm{PI}$ or $\mathrm{PI}-2 \mathrm{PI}$ & $\mathrm{L}$ & ST & $\mathrm{Bc}$ & $\mathrm{FF}$ & FF \\
\hline $\mathrm{N}$ or $\mathrm{VF}$ & VF & VF & 0 & $\mathrm{~N}$ & $\overline{F F}$ or $\mathrm{Bc}$ & ST & $\bar{F}$ & $F$ \\
\hline VF & $\mathrm{F}$ & $\mathrm{N}$ or $\mathrm{VF}$ & $0-\mathrm{PI}$ & $\mathrm{N}$ & ST & $\mathrm{FF}$ or $\mathrm{Bc}$ & ST & $\mathrm{Bc}$ \\
\hline
\end{tabular}

Group 5 is composed of 24 rules of 119 ones that form RTCS. This group is similar to the previous group respect to the values of s1, s2 and s3, but opposite respect to angle and distance values. In this case, angle values define, in almost all rules, situations where the robot is aligned with the objective. As distance value, in most of the rules, corresponds with Far or Very Far distance situation, the combined effect of angle and distance values cause that rules compel the robot to advance straight to the objective. 
Table 6: Group 6 rules.

\begin{tabular}{|c|c|c|c|c|c|c|c|c|}
\hline \multicolumn{7}{|c|}{ CONDITION } & MES \\
\hline s1 & s2 & s3 & a & d & v1 & v2 & v1 & v2 \\
\hline FF & F & FF & 2PI & VN or N & F & F or FF & F & F \\
\hline FF & F or VF & F & 0 & FF & F & F & F & F \\
\hline F & F & F or VF & 2PI & N & ST or F & All & ST & Bc \\
\hline FF & FF & F & PI-2PI & FF & FF or Bc & ST or F & Bc & ST \\
\hline FF & F & FF & 0-PI & FF & FF or Bc & FF & ST & Bc \\
\hline F & FF & FF & 0-PI & N or FF & Bc & ST & ST & Bc \\
\hline FF & F & F & 2PI or 0-PI & F or VF & ST or F & All & F & F \\
\hline FF & F & FF & 0-PI & FF & ST or Bc & ST or Bc & F & F \\
\hline F or VF & F & F or VF & 0 & F or VF & FF & FF or Bc & ST & Bc \\
\hline FF & FF & F & 0 or PI-2PI & FF & FF & FF & ST & Bc \\
\hline FF & F or VF & F & PI-2PI & FF & F & ST or F & F & F \\
\hline F & FF & F or VF & 2PI & N & Bc & ST or Bc & Bc & ST \\
\hline F & FF & FF & PI-2PI & F or VF & Bc & ST & Bc & ST \\
\hline FF & F & FF & 0 & F or VF & F & F & F & F \\
\hline
\end{tabular}

Group 6 consists of 14 rules of 119 that contains RTCS. This group is similar to Group 3 but the represented angle situations require rules that make the robot turns. So, groups 3 and 6 seem to be responsible for approaching the robot to the objective, while groups 1 and 2 seem to be responsible from avoiding obstacles.

The analysis of groups shows the capacity of Classifier Systems to evolve coherent rules groups. This coherence can be seen from two points of view, on one hand, all rules of each group represent similar situations and give similar outputs and, on the other hand, independent behaviors are discriminated, so groups are quite independent. Furthermore, only groups necessary to solve the problem are generated, not all the possible. This allows to conclude that the number of bits to represent possible groups must permit the evolution of all necessary groups and the RTCS will learn the number of groups that are actually necessary.

\section{Conclusions}

This work has been centered in the application of a new CS, named Reactive with Tags Classifier System (RTCS), to learn symbolic rules in a navigation problem. Navigation of a robot could be defined as a complex behavior that requires the movement in a world with obstacles and where the robot goal is to reach a predefined point. This problem, from the point of view of learning, is considered sufficiently complex if the decision must be obtained in real time, since the environment continues changing during the time of taking a decision, or, from another point of view, the robot is moving while the decision is taken.

The RTCS contains a set of mechanisms that allow the incorporation of new environmental information in the process of taking decisions. This process allows rules sequence (chaining rules in different execution instants) and break the sequence to provide a reactive output. The RTCS has proven the capacity of learning reactions and strategies, so the dilemma between reactive and planned systems could be surpassed. 


\section{References}

[1] J.Holland, "Adaptation in Natural an Artificial Systems". University of Michigan Press, Ann Arbor, (1975).

[2] J.Holland, "Adaptive Algorithms for Discovering and Using General Patterns in Growing Knoledge Bases", Int. J. Policy Analysis and Information Systems, vol 4, 245-268, (1980).

[3] J.Holland, "Properties of the Bucket Brigade". In Proc. of International Conference on Genetic Algorithms and their Applications, vol 1, 1-7, (1985).

[4] Holland, J.H. "Hidden order : how adaptation builds complexity". Reading (Massachusetts), Addison-Wesley, (1995).

[5] L. Booker, D.E. Goldberg y J.H. Holland, "Classifier Systems and Genetic Algorithms", Artificial Intelligence, 235-282, (1989).

[6] D.E. Golberg, "Genetic Algorithms in Search, Optimization, and Machine Learning". Addison Wesley, Reading MA, (1989).

[7] M. Mitchell, "An Introduction to Genetic Algorithms", MIT Press, Massachusetts, (1996).

[8] A. Sanchis, J.M. Molina y P. Isasi, “Classifier Systems for Learning Reactions in Robotic Systems", $1^{\text {st }}$ Int. Workshop on Machine Learning, Forecasting and Optimization (MALFO'96), 153-159 (1996).

[9] A Sanchis, J.M. Molina y P. Isasi, "Learning Reactive Behavior for Autonomous Robots using Classifier Systems", Vol. 37 of Frontiers in Artificial Intelligence and Applications, Pag. 152-159, IOS Press, 1997.

[10] R.A. Brooks, "Intelligence Without Representation", Artificial Intelligence, 47, 139-159, (1991).

[11] M.A. Lee y H. Takagi, "Integrating Design Stages on Fuzzy Systems Using Genetic Algorithms". $2^{\text {nd }}$ Int. Conf. on Fuzzy Systems, 612-617, (1993).

[12] J.M. Molina, A. Sanchis, A. Berlanga, P.Isasi-Viñuela, "Evolving Connection Weight Between Sensors and Actuators in Robots". IEEE International Symposium on Industrial Electronics. (1997).

[13] F. M Mondada y P.I. Franzi , "Mobile Robot Miniaturization: A Tool for Investigation in Control Algorithms". Proc. $2^{\text {nd }}$. Int. Conf. on Fuzzy Systems. San Francisco, USA, (1993).

[14] M. Dorigo, "ALECSYS and the AutonoMouse: Learning to Control a Real Robot by Distributed CS”, Machine Learning, 19, 209-240, (1995).

[15] G. Wei $\beta$, "Hierarchical Chunking in Classifier Systems", Proc. of the $12^{\text {th }}$. International Conference on Artificial Intelligence", 1335-1340, (1994).

[16] S. Wilson, "Knowledge growth in an Artificial Animal", Proc. of the First Int. Conf. on Genetic Algorithms and their Applications, 16-23, (1985).

[17] J.J. Grefenstette, "Credit Assignment in Rule Discovery Systems Based on Genetic Algorithms", Machine Learning, vol 3, 225-245, (1988). 